\title{
The Effect of Technical Competence in Balance Elements of Rhythmic Gymnastics on the Sportive Success of Taekwondo Poomsae Athletes
}

\author{
Sezen Çimen Polat \\ Correspondence: Sezen Çimen Polat, Gazi University Sports Sciences Faculty, Turkey. \\ Received: June 19, 2018 \\ doi:10.11114/jets.v6i9.3375 \\ Online Published: August 6, 2018 \\ URL: https://doi.org/10.11114/jets.v6i9.3375
}

\begin{abstract}
This study aims to investigate the effect of technical competence in certain balance elements, an important parameter in rhythmic gymnastics, on sportive success in taekwondo poomsae athletes and the relationship between them. The study was conducted on 12 female taekwondo athletes (age: 17.6 \pm 1.2 ; height: $159.26 \pm 3.1 \mathrm{~cm}$; weight: $50.79 \pm 1.82 \mathrm{~kg}$; BMI: $20.88 \pm 0.98 \mathrm{~kg} / \mathrm{m}^{2}$ ). The participants were selected from successful athletes who were in the top 6 in their own category in the national taekwondo competition held this year. The athletes performed 6 balance elements in rhythmic gymnastics, i.e. side passé (SP), $90^{\circ}$ forward $\left(90^{\circ} \mathrm{F}\right)$, side split with hand support (SSWHS), Arabesque with trunk forward (A), Cossack (C) and free leg to the side (FLS), and the Y balance test. The relationship between these balances that were assessed by 3 international judges and success rating was identified using the Spearman correlation test. The level of significance was accepted as $\mathrm{p}<0.05$. As result, a statistically significant difference was found between side passé and split with hand support, balances used in rhythmic gymnastics, and success ratings $(\mathrm{p}<0.05)$. While no statistically significant difference was found between other balances, i.e. $90^{\circ}$ forward, arabesque with trunk forward, cossack and free leg to the side and sportive success, there was a high relationship between them. In addition, there was no statistically significant difference between sportive success and right and left anterior (RAB, LAB) posteromedial (RPMB, LPMB) and posterolateral (RPLB, LPLB) reach distances. In conclusion, since the study found a high relationship between sportive success and technical competence of poomsae athletes in the two technical side balances, it is suggested that basic gymnastics training can be effective in improving the balancing skills of taekwondo poomsae athletes.
\end{abstract}

Keywords: gymnastics, taekwondo poomsae, balance, sportive success

\section{Introduction}

Gymnastics is considered as the basis of all sports and gymnastics training is important for all sports branches. The training contributes not only to motor performance but also motor development. Gymnastics also helps to correct and improve physical structure of the body and posture easily. In addition, motor skills required in other branches are easily acquired through gymnastics training. This is one of the reasons that athletes with basic gymnastics training become successful rapidly and easily in other branches as well. Rhythmic gymnastics and taekwondo poomsae are two different sports branches that require the execution of movements with the right technique, a sense of aesthetics and visual harmony. Both are among rare branches in which successful execution of movements is as important as gaining sportive achievement. In both branches, a high level of flexibility and well-improved balance are two essential motor abilities that lead athletes to success. In rhythmic gymnastics, music, dancing steps and gestures play an important role in the execution of competition series. The ability to move with music requires an improved sense of rhythm. The dance should be in harmony with the rhythms and gymnast should embroider the music, so to say, with each one of her movements. The aesthetics in the execution of body elements with high level of difficulty is another important detail in rhythmic gymnastics which is a visual sports. The athlete should give to the audience the impression that she can perform the movements with great ease (Konter, 1998). In addition, gymnasts have superior balancing skills compared to athletes in other sports branches as they perform static balance in difficult postures and dynamic landings after acrobatic skills (Sloanhoffer, Harisson, Mccrory, 2018). Furthermore, balance is one of the elements that should be included in rhythmic gymnastics series according to the rules set by the Fédération Internationale de Gymnastique (FIG) (FIG Code of points, 2017-2020). As for taekwondo, it is an Olympic sports characterized with extensive use of kicking techniques that require a considerable amount of explosive force and agility (Valenzuela et al, 2016). It integrates agility, strength, speed, balance, flexibility, coordination and resistance that athletes need to perform highly challenging kicking 
combinations (Shin, Lee, Noh, Kwak, 2013). World Taekwondo divides this sports into two categories: Gyorugi and Poomsae (Noh, Kim, Kim, 2013). Poomsae was recognized and accepted as a competitive sport branch by the World Taekwondo in 2000 since it requires skills, technique and physical strength (Kazemi, Ingar, Jaffery, 2016). This form of taekwondo is the combination of offensive and defensive skills that use the whole body for mental concentration and discipline. It is important in poomsae to perform motion with accuracy, competence and impressiveness (Noh et al., 2013). The execution of poomsae has an artistic aspect. Poomsae practitioners not only need to execute movements through the right technique but they also perform basic movements with an artistic approach and express a combination of taekwondo philosophy and ethics. Poomsae can also be considered as the way of conduct that expresses mental and physical improvements directly or indirectly as well as the principles of offense and defence stemming from the nurturing of taekwondo spirit and techniques (Shin et al, 2016). What rhythmic gymnastics and taekwondo poomsae have in common is that both are performed using the right technique and both have a sense of aesthetics and visual harmony in the execution of movements. Besides, balance and flexibility are important motor elements for both branches. Based on this point of view, this study was conducted to examine the impact of technical competence in certain balances, an important parameter in rhythmic gymnastics, on the sportive success of taekwondo poomsae athletes and the relationship between them.

\section{Material and Method}

The study was conducted on 12 female taekwondo athletes who were actively engaged in taekwondo poomsae and competed in the National Taekwondo Championship in 2018 (4 in cadet, 4 in junior and 4 in senior category). All the taekwondo practitioners were successful athletes who were in the top 6 in their own categories and had no injury. Before measurements, the study was explained in detail to the athletes, their families and trainers. Informed consent forms were taken from the families of the athletes who volunteered to participate in the study. Ethical committee approval no: 2018-230 in 05.06.2018 was obtained to carry out this study from the Ethical Committee of Gazi University. The measurements completed in 1 day were conducted in a sports hall in the Faculty of Sports Sciences of Gazi University. Detailed information sheets including figures and explanations on the balance elements to be assessed were handed out to the athletes half an hour before measurement, and then, a gymnast performed the movements so that they could learn the balances accurately. First of all, the athletes' body weight, body fat percentage and body mass index were assessed using Tanita body composition analyzer. After a general warm-up, anterior, posteromedial and posterolateral reach distances were measured through the Y balance test while flexibility was assessed using "sit and reach" test. Following 2 attempts for each measurement, the best performance was recorded to be used in the study. Balance was measured through Y balance test. After the taekwondo athletes preserved their balance for a while on one leg at the determined centre, the farthest distances they could reach in anterior, posteromedial and posterolateral directions were marked using a tape. (Plisky et al., 2006). Sit and reach test was performed using standart procedures with reach box. It was placed on the floor, by placing tape at a right angle to the $38 \mathrm{~cm}$ mark. The participant sat on the floor with no shoes on, and fully extended one leg so that the sole of the foot was flat against the end of the box. She then extended her arms forward. With palms down, she reached forward sling hands along the measuring scale as far as possible without bending the knee of the extended leg (Baltac1 et al., 2002). Later, the athletes performed 6 balances used in gymnastics with 3 trials for each shape. These performances were assessed by 3 active judges from the Fédération Internationale de Gymnastique (FIG) on a scale of 1-5. The taekwondo athletes' sports age and success ratings in the National Taekwondo Championship 2018 were also recorded.

In statistical analysis, the relationships between the data were identified using the Spearman correlation test and the level of significance was accepted as $\mathrm{p}<0.05$. Thus, the relationship between competence in performing balance elements and sportive success in taekwondo practitioners was revealed. 


\begin{tabular}{|l|l|}
\hline & Side passé (SP) \\
\hline & $90^{\circ}$ forward $\left(90^{\circ} \mathrm{F}\right)$ \\
\hline & Side split with hand support (SSWHS) \\
\hline
\end{tabular}

Figure 1. Technical balance elements performed by the taekwondo athletes

\section{Findings}

Table 1. Relationship between Technical Balances (1-5 scale) and Sportive success

\begin{tabular}{lcccccc}
\hline TECHNICAL BALANCES & & & & & \\
\hline SP & & $90^{\circ} \mathrm{F}$ & SSWHS & $\mathrm{A}$ & $\mathrm{C}$ & FLS \\
\hline Mean (scale 1-5) & 4.55 & 4.18 & 4.27 & 3.55 & 4.27 & 2.73 \\
\hline Standart Deviatition $( \pm)$ & $(0.26)$ & $(0.3)$ & $(0.27)$ & $(0.29)$ & $(0.29)$ & $(0.34)$ \\
\hline $\mathrm{p}$ & $0.03^{*}$ & 0.80 & $0.04^{*}$ & 0.28 & 0.78 & 0.45 \\
\hline $\mathrm{r}$ & -0.652 & -0.087 & -0.616 & -0.359 & -0.095 & 0.257 \\
\hline
\end{tabular}

$\mathrm{p}<0.05$

The examination of Table 1 indicates a statistically significant difference between side passé and side split with hand support and success ratings $(\mathrm{p}<0.05)$. While there was no significant difference between other balances, i.e. $90^{\circ}$ forward, arabesque with trunk forward, cossack and free leg to the side, and success ratings, a high relationship was found between them.

Table 2. Relationship between the Y Balance Test and Sportive Success

\begin{tabular}{lcccccc}
\hline Y BALANCE TEST & \multicolumn{7}{c}{} & & \\
\hline & & RPMB & RPLB & LAB & LPMB & LPLB \\
RAB & & & & & \\
Mean $(\mathrm{cm})$ & 69.5 & 79.5 & 79.3 & 69 & 81.5 & 80.7 \\
Standart Deviation $( \pm)$ & 1.47 & 1.8 & 2.28 & 2.7 & 2.61 & 2.44 \\
$\mathrm{p}$ & 0.19 & 0.29 & 0.38 & 0.44 & 0.97 & 0.86 \\
$\mathrm{r}$ & -0.42 & -0.35 & -0.29 & -0.26 & 0.01 & -0.06 \\
$\mathrm{p}<0.05$ & & & & & &
\end{tabular}

The examination of Table 2 reveals no statistically significant difference between anterior, posteromedial and posterolateral reach distances in the Y balance test for both feet, and sportive success.

\section{Conclusion}

At the end of the study, a statistically significant difference was identified between side passé and side split with hand support, balances used in rhythmic gymnastics, and success ratings $(\mathrm{p}<0.05)$, which means that top rankings in competitions are occupied by taekwondo athletes who have better knowledge of gymnastics elements. Thus, it is concluded that basic gymnastics training can be an effective method for enhancing the balancing skills of taekwondo poomsae athletes.

\section{Discussion}

The study was conducted on 12 female taekwondo athletes (age: $17.6 \pm 1.2$; height: $159.26 \pm 3.1 \mathrm{~cm}$; weight: $50.79 \pm 1.82 \mathrm{~kg}$ and BMI: $20.88 \pm 0.98 \mathrm{~kg} / \mathrm{m}^{2}$ ) who were actively engaged in taekwondo poomsae sports and participated in the National Taekwondo Competition held this year. The results of the study enlighten us about the significance of having knowledge of balance which is peculiar to gymnasts for achieving better results in poomsae athletes in taekwondo that requires a significant amount of body control. The findings suggest a statistically significant difference between (SP) and (SSWHS), balances used in rhythmic gymnastics (Table 1), and sportive success $(\mathrm{p}<0.05)$. While there was no statistically significant difference between other balances, i.e. $\left(90^{\circ} \mathrm{F}\right),(\mathrm{A}),(\mathrm{C})$ and (FLS), and sportive success, a high relationship was found between them. In addition, no statistically significant difference was identified between sportive success and (RAB), (LAB), (RPMB), (LPMB), 
(RPLB), (LPLB) (Table 2). In rhythmic gymnastics, balances are executed on the foot, on the toes or different parts of the body. Regardless of how the balance is performed, an important point is defining the balance shape with accuracy and right technique. Another important point is maintaining body control and fixing the balance elements that define the shape accurately, which requires maintaining this posture at least for $1 \mathrm{sec}$ (FIG Code of points, 2017-2020). The balance elements used in the study were selected from over 40 balances in the rhythmic gymnastics code of points manual. These balances do not require specific gymnastics knowledge and are considered easier to perform in terms of scoring. However, diversity was taken into consideration in their selection and the assessment was made with a wide range of balances that the free leg is extended to different directions such as forward, side and backward, and shapes performed on foot, crouching position or leg. To perform kick techniques like side kick and roundhouse kick in taekwondo poomsae, the support leg is rotated inward by $30^{\circ}$ (Lee\&Kim, 2007). In this case, hip joint reaches to a side opening. Thus, taekwondo athletes are used to situations in which elements such as joint opening, balance and strength are executed to the sides when performing such movements. It is found that the significant results obtained from the study stem from (SP) and (SSWHS) that involves technical extension of the leg to the side. It is assumed that these significant results were derived from the balances that use techniques to extend the leg to the side in accordance with the general characteristics of poomsae taekwondo. However, the results for (C) performed in hunkering position and 'free leg to the side' performed on the knee were not significant as they do not comply with the general characteristics of taekwondo that is performed in a standing position. In terms of technical aspects, while there is an evident relationship between balance elements and poomsae techniques, gymnastics as a main sports branch contributes to the development of motor skills needed in all sports branches (Atılgan\&Pınar, 2005), (Ateş, Çetin, Yarım, 2017). The main objectives of gymnastics training is developing basic motor skills such as strength, movement coordination, flexibility, balance and speed, and improving conscious control of the movement and position of the body (Lesnik, Glinsek, Zvan, 2015). Balance control is a complex motor ability that involves planning and performing flexible shapes as well as the integration of sensory inputs (Ferdjallah, Harris, Smith, Wertsch, 2002). This ability is the most important element that gymnastics training starting at small ages aims to achieve. Various studies in literature indicate that many motor abilities develop rapidly and accurately thanks to the basic training required in gymnastics. In their study examining basic gymnastics program in terms of motor development in preschool children, Durukan, Koyuncuoğlu and Şentürk (2016) found that 16 week basic gymnastics training resulted in a significant improvement in children's balancing ability. Another study (Garcia, Barella, Viana, Barela, 2011) revealed that gymnastics training supported the development of postural control in children. In another study, Serbes (2010) concluded that regular gymnastics training significantly enhanced basic physical and physiological parameters such as flexibility, strength, coordination and balance in 8-10 years old girls. All these studies demonstrate the positive relationship between basic gymnastics training and improved balance. Furthermore, other studies that compared sports branches associated with balance revealed that gymnasts have superior balancing skills than athletes in other branches. In this context, in his study comparing dynamic balance in high level female and male gymnasts, swimmers, soccer players and individuals with no formal sports experience, Davlin (2004) states that gymnasts performed better than the athletes in other groups. In addition, Bressel (2007) who compared dynamic and static balance in collegiate soccer, basketball, and gymnastics athletes maintains that gymnastics and soccer athletes had better dynamic balance scores than basketball players. While we have found no study on poomsae branch with regard to these parameters that are essential in gymnastics, the explanations on different forms of taekwondo involving defence techniques reveal that balance is important in taekwondo which is usually characterized as a competitive sports performed against an opponent, and thus, balance should be included in taekwondo training programs (Kim, 1986). That is because a balanced posture in taekwondo prepares athletes for changes to come while moving and give them flexibility to move depending on the positioning distance and actions of their opponents. A good posture allows taekwondo athletes to maintain their balance, react against their opponents' actions and change their gravitational centre when necessary (Kill, 2006). A study on balance parameter in taekwondo athletes that compared the balancing skills of individuals with low level of taekwondo training (1-3 years) and healthy sedentary people (Hio-Teng, Siu, Gabriel, William, 2011) found that people with taekwondo training had statistically better balance performance and recommended that people with balance problems could benefit from taekwondo training. In another study, Tekin (2016) examined the balance performance of athletes engaged in athletics, wresting and taekwondo and found that wrestlers had higher balancing scores on a flat surface compared to athletes and there was no significant difference between athletics and taekwondo, and wrestling and taekwondo. Our study investigated the impact of competence in gymnastics elements on performance since balance constitutes an important part of training process in taekwondo categories and revealed a high relationship between sportive success and technical competence of poomsae athletes, particularly in two technical side balances. To conclude, it is considered that basic gymnastics training can be an effective method for improving the balancing skills of taekwondo poomsae athletes.

\section{References}

Ateş, B., Çetin, E., \& Yarim, E. (2017). Balance ability and balance training in female athletes. Gaziantep University Journal of Sports Science, 2(2), 66-79.

Atılgan, O., \& Pınar, S. (2005). Evaluation of the effect of rhythm education on acquiring complex gymnastics skills. 
Gazi Journal of Physical Education and Sports Sciences, 10(2), 11-24.

Baltacı, G., Un, N., Tunay, V., Besler, A., \& Gerçeker, S. (2002). Comparison of three different sit and reach tests for measurement of hamstring flexibility in female university students. British Journal of Sports Medicine, 37, 59-61. https://doi.org/10.1136/bjsm.37.1.59

Durukan, H., Koyuncuoğlu, K., \& Şentürk, U. (2016). Investigation of basic gymnastics program in terms of motor development among pre-school children. Celal Bayar University Journal of Physical Education and Sports Sciences, 1(2), 131-140.

Ferdjallah, M., Harris, G. F., Smith, P., \& Wertsch, J. J. (2002). Analysis of postural control synergies during quiet standing in healthy children and children with cerebral palsy. Clinical Biomechanics, 17(3), 203-210. https://doi.org/10.1016/S0268-0033(01)00121-8

FIG Executive Committe (2017-2020). FIG Code of Points: Rhythmic Gymnastics.

Garcia, C., Barela, J., A., Viana, A., R., \& Barela, A., M., F. (2011). Influence of gymnastics training on the development of postural control. Neuroscience Letters, 492(1), 29-32. https://doi.org/10.1016/j.neulet.2011.01.047

Hio-Teng, L., Siu, N. F., Gabriel, Y., Ng, F., \& William, W. N. (2011). Tsang. Low-level taekwondo practitioners have better somatosensory organisation in standing balance than sedentary people. European Journal of Applied Physiology, 111(8), 1787-1793. https://doi.org/10.1007/s00421-010-1798-7

Kazemi, M., Ingar, A., \& Jaffery, A. (2016). Injuries in elite taekwondo poomsae athletes. Journal of the Canadian Chiropractic Association, 60(4), 330-341.

Kill, Y. S. (2006). Competitive taekwondo: winning training and tactics. USA: Human Kinetics.

Kim., J. R. (1986). Taekwondo., Seoul- Korea: Seo Lim Publishing Company.

Konter, A. (1998). Sportif Ritmik Cimnastik. İstanbul: İnkılap Kitabevi.

Lee, K. H., \& Kim, S. H. (2007). Complete taekwondo poomse: the official taegeuk, palgwae and black belt forms of taekwondo. USA: Turtle Press.

Lesnik, B., Glinsek, V., \& Zvan, M. (2015). Correlation between gymnastics elements knowledge and performance success in younger categories of alpine skiing. Science of Gymnastics Journal, 7(2), 67-79.

Noh, J. W., Kim, J. H., \& Kim, J. (2013) Somatotype analysis of elite taekwondo athletes compared to non- athletes for sports health sciences. The Korean Society of Environmental Risk Assessment and Health Science and Springer. https://doi.org/10.1007/s13530-013-0178-1

Plisky, P. J., Rauh, M. J., Kaminski, T. W., \& Underwood, F. B. (2006). Star excursion balance test as a predictor of lower extremity injury in high school basketball players. Journal of Orthopaedic \& Sports Physical Therapy, 36(12), 911-919. https://doi.org/10.2519/jospt.2006.2244

Serbes H. (2010). Effects of gym programs applied to girls aged 8-10 to their some physical and physicometric parameters. (Master Thesis, Dumlupınar University Institute of Health Sciences), Kütahya.

Shin, Y. S., Lee, L. K., Noh, J. W., \& Kwak, T. Y. (2016). Differences in respirogram phase between taekwondo poomsae athletes and nonathletes. The Journal of Physical Therapy Science, 28(9), 2495-2500. https://doi.org/10.1589/jpts.28.2495

Sloanhoffer, H. L., Harisson, K. D., \& Mccrory, J. L. (2018). Dynamic stability in gymnasts, non-balance athletes, and active controls. International Journal of Exercise Science, 11(1), 1-12.

Tekin, Y. S. (2016). The examining of balance performance in athletics, wrestling and taekwondo athletes. (Master Thesis, Selçuk University Institute of Health Sciences), Konya.

Valenzuela, T. H., Badilla. P. V., Francini. E., Santos, J. F. S., Campillo, R. R., Hermoso, A. G., ... \& Gomez, J. P. S. (2016). Effects of multi-component training on the physical fitness of young taekwondo athletes. Journal of Martial Arts Anthropology, 16(4), 31-37.

\section{Copyrights}

Copyright for this article is retained by the author(s), with first publication rights granted to the journal.

This is an open-access article distributed under the terms and conditions of the Creative Commons Attribution license which permits unrestricted use, distribution, and reproduction in any medium, provided the original work is properly cited. 